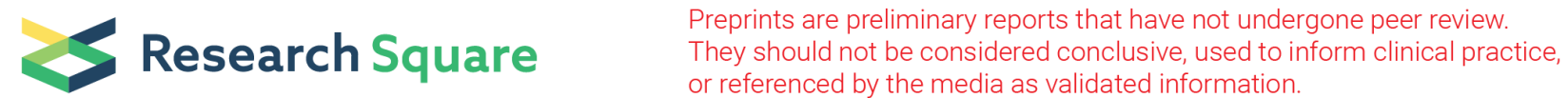

\section{Modified TruSeq Small RNA Library Prep using Randomized 4N Adapters: In house 4N Protocol D}

\section{Giraldez ( $\nabla$ mgiralde@med.umich.edu )}

Department of Internal Medicine, University of Michigan, Ann Arbor, MI

\section{Tewari ( $\nabla$ mtewari@med.umich.edu )}

Departments of Internal Medicine and Biomedical Engineering, Center for Computational Medicine and Bioinformatics, and Biointerfaces Institute, University of Michigan, Ann Arbor, MI

\section{DJ Galas ( $\nabla$ dgalas@pnri.org)}

Pacific Northwest Research Institute, Seattle, WA

\section{TAP Driedonks}

Department of Biochemistry and Cell Biology, Faculty of Veterinary Medicine, Utrecht University, The Netherlands

\section{LC Laurent}

Department of Reproductive Medicine and Sanford Consortium for Regenerative Medicine, University of California San Diego

\section{PG Woodruff}

Cardiovascular Research Institute and the Department of Medicine, Division of Pulmonary, Critical Care, Sleep, and Allergy, University of California San Francisco

\section{JE Freedman}

Department of Medicine, Division of Cardiovascular Medicine, University of Massachusetts Medical School, Worcester, MA

\section{K Van Keuren-Jensen}

Neurogenomics, The Translational Genomics Research Institute (TGen), Phoenix, AZ

\section{Y Wang}

Center for Cancer Computational Biology, Dana-Farber Cancer Institute, Boston, MA

\section{Ghiran}

Department of Medicine, Beth Israel Deaconess Medical Center, Harvard Medical School, Boston, MA

\section{K Wang}

Institute for Systems Biology, Seattle, WA

\section{H Jiang}

Center for Computational Medicine and Bioinformatics and Department of Biostatistics, University of Michigan, Ann Arbor, MI

\section{ENM Nolte-t Hoen}

Department of Biochemistry and Cell Biology, Faculty of Veterinary Medicine, Utrecht University, The Netherlands 


\section{HPJ Buermans}

14 Leiden Genome Technology Center, Department of Human Genetics, Leiden University Medical Center, The Netherlands

\section{R Rubio}

Center for Cancer Computational Biology, Dana-Farber Cancer Institute, Boston, MA

\section{Baxter}

Institute for Systems Biology, Seattle, WA

\section{J Khoory}

Department of Medicine, Beth Israel Deaconess Medical Center, Harvard Medical School, Boston, MA

\section{S Lu}

Department of Medicine, Beth Israel Deaconess Medical Center, Harvard Medical School, Boston, MA

\section{A Courtright}

Neurogenomics, The Translational Genomics Research Institute (TGen), Phoenix, AZ

\section{K Tanriverdi}

Department of Medicine, Division of Cardiovascular Medicine, University of Massachusetts Medical School, Worcester, MA

\section{PL De Hoff}

Department of Reproductive Medicine and Sanford Consortium for Regenerative Medicine, University of California San Diego

\section{S Srinivasan}

Department of Reproductive Medicine and Sanford Consortium for Regenerative Medicine, University of California San Diego

\section{AJ Barczak}

Lung Biology Center, Department of Medicine, University of California San Francisco

\section{PM Godoy}

Lung Biology Center, Department of Medicine, University of California San Francisco

\section{A Etheridge}

Pacific Northwest Research Institute, Seattle, WA

\section{RM Spengler}

Department of Internal Medicine, University of Michigan, Ann Arbor, MI

\section{DJ Erle}

Lung Biology Center, Department of Medicine, University of California San Francisco

\section{Method Article}

Keywords: small RNA sequencing, 4N adapters, small RNA library preparation, extracellular RNA, exRNA, ERCC

Posted Date: May 15th, 2018 
DOI: https://doi.org/10.1038/protex.2018.052

License: (c) (1) This work is licensed under a Creative Commons Attribution 4.0 International License. Read Full License 


\section{Abstract}

This protocol describes a library preparation method for sequencing small RNA. The method uses degenerate adapters to alleviate the problem of bias in the ligation steps during small RNA library preparation, and it optimizes several other parameters to make it appropriate for use specifically with plasma RNA.

\section{Introduction}

Extracellular RNAs $\backslash$ (exRNAs) have been identified in every biofluid that has been tested. In biofluids, they have been found in extracellular vesicles, ribonucleoprotein complexes, and lipoprotein complexes. ExRNAs are of considerable interest because they can serve as signaling molecules between cells, they have the potential to serve as biomarkers for prediction and diagnosis of disease, and exRNAs or the extracellular particles that carry them might be used for therapeutic purposes. The Extracellular RNA Communication Consortium $\backslash(E R C C)$ is a group of laboratories funded by the U.S. National Institutes of Health. One goal of the ERCC is to develop robust and standardized methods for collecting and processing of biofluids, separating different types of exRNA-containing particles, and isolating and analyzing exRNAs. The "Reference Profiles group":http:// exrna.org/referenceprofiles/ within the consortium is tasked with collecting reliable profiles of the spectrum of extracellular RNAs found in healthy individuals. These reference profiles will serve as benchmarks for comparison with the exRNA profiles from patients with disease. The present protocol for small RNA library preparation was developed by the ERCC Reference Profiles group for use with RNA isolated from human plasma. Key elements of this small RNA library preparation method include the use of 4 random nucleotides on the end of the adapters ligated to the small RNAs of interest, the use of higher than usual adapter concentrations, and the use of increased amounts of polyethylene glycol \(PEG) in the ligation steps. Small RNA library preparation methods that lack such degenerate adapters have been found to exhibit significant bias in the representation of different RNA sequences. ${ }^{1-4}$ The use of random adapters is designed to alleviate that problem. The use of high adapter concentrations and macromolecular crowding agents such as PEG reduces bias by driving the ligation reactions toward completion. It should be noted that the use of improved ligation conditions and increased adapter concentrations also results in the formation of more adapter dimers, so purification of desired ligation products from such unwanted side products by size fractionation is essential in this protocol. **PCR amplification** Small RNA libraries may require 10-20 cycles of PCR amplification depending on the type and amount of input. It has been shown that increased amplification does not significantly affect library bias. ${ }^{1,5}$ Increased number of PCR cycles will, however, increase the amount of adapter dimers that must be separated from the library. Typically, a single PCR and gel purification step is sufficient to remove most of the adapter dimer products from insert-containing PCR products. ${ }^{*}$ Size selection ${ }^{\star *}$ Because of the large excess of adapter dimers in lowinput small RNA libraries, electrophoretic purification of PCR products is often necessary. This can be done using either acrylamide or agarose gels, as long as the gel can sufficiently resolve the insertcontaining fragments $\backslash(==150 \mathrm{bp})$ from the adapter dimer fragments $\backslash(==125 \mathrm{bp})$. A full list of the protocols 
developed by the ERCC is available at the "exRNA Portal":http://exrna.org/resources/protocols/, the ERCC's website. This protocol is one of four protocols relating to a 2018 Nature Biotechnology paper. Library Preparation for small RNA sequencing using 4N adapters: In house 4N Protocol A "10.1038/protex.2018.049":http://dx.doi.org/10.1038/protex.2018.049 Library Preparation for small RNA sequencing using $4 \mathrm{~N}$ adapters: In house $4 \mathrm{~N}$ Protocol $\mathrm{B}$

"10.1038/protex.2018.050":http://dx.doi.org/10.1038/protex.2018.050 Library Preparation for small RNA sequencing using $4 \mathrm{~N}$ adapters: In house $4 \mathrm{~N}$ Protocol $\mathrm{C}$ "10.1038/protex.2018.081":http://dx.doi.org/10.1038/protex.2018.081/ Modified TruSeq Small RNA Library Prep using Randomized 4N Adapters: In house 4N Protocol D

"10.1038/protex.2018.052":http://dx.doi.org/10.1038/protex.2018.052

\section{Reagents}

**Oligonucleotide sequences ${ }^{* * 1}-5^{\prime}$ adapter $\backslash($ desalted $)-5^{\prime}$ rGrUrUrCrArGrArGrUrUrCrUrArCrArGrUrCrCrGrArCrGrArUrCr\(N:2525252525)r $\backslash(\mathrm{N}) r(\mathrm{~N}) r(\mathrm{~N}) r(\mathrm{~N})-\mathrm{3}^{\prime}-3^{\prime}$

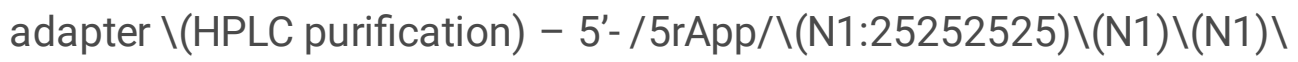
(N1)TGGAATTCTCGGGTGCCAAGG/3ddC/-3' ** Reagents for 3' Ligation** - TruSeq Small RNA Kit $\backslash$ (Illumina RS-200-0012) - T4 RNA Ligase 2, Deletion Mutant \(NEB M0242) - 50\% PEG $8000 \backslash$ (included with T4 RNA ligase) - Strip tubes $\backslash$ (Axygen PCR-0208-CP-C or equivalent) **Reagents for adapter depletion** _ _E. coli_ single-stranded DNA binding protein $\backslash($ SSB $) \backslash($ Promega M3011) - 5' deadenylase $\backslash$ (NEB M0331) - RecJf $\backslash($ NEB M0264) **Reagents for 5 ' Ligation** - 10mM ATP and T4 RNA ligase 1 from TruSeq Small RNA Kit **Reagents for Reverse Transcription** - RNA RT primer, $25 \mathrm{mM}$ dNTP mix and RNase inhibitor from TruSeq Small RNA Kit - SuperScript II \(Invitrogen 18064-014) - 5x First strand buffer $\backslash$ (included with Superscript II) - 0.1 M DTT \(included with Superscript II) - Strip tubes \(Axygen PCR-0208CP-C or equivalent) **Reagents for PCR Amplification** - TruSeq Small RNA Kit ** Reagents for Gel Purification** - 3\% agarose cassettes for Pippin Prep \(Sage Science CDP3010) - QIAquick PCR purification kit \(Qiagen 28104) **Reagents for Library Validation** - High sensitivity DNA chip for Bioanalyzer $\backslash$ (Agilent 5067-4626)

\section{Equipment}

**Equipment for Ligations and Reverse Transcription** - Vacuum concentrator - Thermal cycler

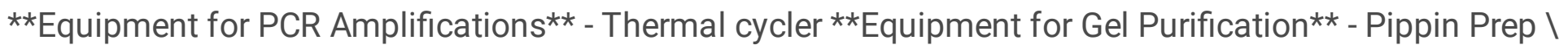
(Sage Science, PIP0001) size selection instrument - Nanodrop spectrophotometer ${ }^{\star \star}$ Equipment for Library Validation** - Agilent 2100 Bioanalyzer

\section{Procedure}

**Thermocycler Setup ${ }^{* *} \quad 70^{\circ} \mathrm{C} \quad 2$ minutes $\quad 28^{\circ} \mathrm{C} \quad 1$ hour $\quad 30^{\circ} \mathrm{C} \quad 45$ minutes $\quad 37^{\circ} \mathrm{C} 45$ minutes $70^{\circ} \mathrm{C} 2$ minutes $\quad 28^{\circ} \mathrm{C} \quad 1$ hour $\quad 70^{\circ} \mathrm{C} \quad 2$ minutes $50^{\circ} \mathrm{C} \quad 1$ hour $\quad 98^{\circ} \mathrm{C} 30$ seconds $98^{\circ} \mathrm{C} 10$ seconds $\quad 60^{\circ} \mathrm{C} 30$ seconds $20 \mathrm{X} \quad 72^{\circ} \mathrm{C} 15$ seconds 
$72^{\circ} \mathrm{C} 10$ minutes $\quad 4^{\circ} \mathrm{C}$ Hold $* \star$ Prepare Adapter Stocks** $3^{\prime}$ adapter: dilute to $4 \mu \mathrm{M}$ in water $5^{\prime}$ adapter: dilute to $10 \mu \mathrm{M}$ in water **Prepare PEG Pellets** 1 . Dilute $50 \%$ PEG to $15 \%$ PEG by adding water. 2. Aliquot $10 \mu \mathrm{L}$ of $15 \%$ PEG to PCR Tube. 3. Dry PEG until it is a pellet. 4. Store in dark conditions. ${ }^{*} 3^{\prime}$ Ligation: Set Up on Ice. ${ }^{\star \star} 1$. Add $1 \mu \mathrm{L}$ of $4 \mu \mathrm{M} 3^{\prime}-4 \mathrm{~N}$ adapter to each tube. 2. Add $5 \mu \mathrm{L}$ of each RNA sample. 3. Gently mix, vortex, and centrifuge. 4. Incubate at $70^{\circ} \mathrm{C}$ for 2 minutes. 5 . Immediately place on ice for 2 minutes. 6. Mix, vortex, and centrifuge. 7. Preheat thermocycler to $28^{\circ} \mathrm{C}$. 8. ${ }^{\star \star}$ Prepare Ligation Master Mix:** Reagent Volume $\backslash(\underline{\mu})_{\text {_ }}$ Ligation Buffer $\backslash(\mathrm{HML})^{2}$

RNase Inhibitor 1 T4 RNA Ligase 2, Deletion Mutant 1 Total Volume per Sample 4 9. Add $4 \mu \mathrm{L}$ of Ligation Master Mix to each tube. 10. Gently mix, Vortex, and Centrifuge. 11. Incubate at $28^{\circ} \mathrm{C}$ for 1 hour. ${ }^{* \star}$ Adapter Depletion ${ }^{\star \star} 12$. Add $1 \mu \mathrm{g}$ of _E. coli_SSBP to each tube $\backslash(1 \mu \mathrm{g} / \mu \mathrm{L}-$ will need to make dilution from stock.) 13 . Incubate on ice for 10 minutes. 14 . Add $1 \mu \mathrm{L}$ of $5^{\prime}$ deadenylase. 15 . Incubate at $30^{\circ} \mathrm{C}$ for 45 minutes. 16 . Add $1 \mu \mathrm{L}$ of RecJf. 17 . Incubate at $37^{\circ} \mathrm{C}$ for 45 minutes. ${ }^{\star} 5^{\prime}$ Ligation ${ }^{\star *} 18$. Preheat thermocycler to $70^{\circ} \mathrm{C}$. 19 . Prepare a master mix by adding $1.1 \times \mathrm{N} \backslash$ ( $\mathrm{N}=$ number of samples) $10 \mu \mathrm{M} 5^{\prime}-4 \mathrm{~N}$ adapter to separate PCR tube. 20 . Incubate at $70^{\circ} \mathrm{C}$ for 2 minutes. 21. Place on ice for 2 minutes. 22. Preheat thermocycler to $28^{\circ} \mathrm{C}$. 23. Add $1.1 \times N \backslash(\mathrm{N}=$ number of samples) $10 \mathrm{mM}$ ATP to the RNA 5' Adapter PCR Tube. 24. Add 1.1 $\times \mathrm{N} \backslash(\mathrm{N}=$ number of samples) T4 RNA Ligase to the RNA 5 ' and ATP PCR Tube. 25. Gently mix, Vortex, and Centrifuge. 26. Add $3 \mu \mathrm{L}$ of the master mix to each sample $\backslash$ (reaction from step 17). 27. Incubate at $28^{\circ} \mathrm{C}$ for 1 hour. 28 . Place on ice for 2 minutes. ${ }^{*}$ Reverse Transcription and Amplification ${ }^{\star *} 29$. Mix, Vortex, and Centrifuge. 30. Concentrate samples down from $14 \mu \mathrm{L}$ to $6 \mu \mathrm{L}$. 31. Add $1 \mu \mathrm{L}$ of RNA RT Primer to each tube. 32. Gently mix and centrifuge briefly. 33. Incubate at $70^{\circ} \mathrm{C}$ for 2 minutes. 34. Place on ice for 2 minutes. 35. Preheat thermocycler to $50^{\circ} \mathrm{C}$. 36. **Prepare RT Master Mix:** Reagent

First Strand Buffer

DTT

RT 1
$212.5 \mathrm{mM}$ dNTP $\mathrm{Mix}^{3}$

1 RNAse Inhibitor Total Volume per Sample
Volume $\backslash(\underline{\mu})_{-} 5 X$

$0.5100 \mathrm{mM}$

\section{SuperScript II}

5.5 37. Add $5.5 \mu \mathrm{L}$ of RT Master Mix to each sample. \(Total volume is $12.5 \mu \mathrm{L}$.) 38. Gently mix, Vortex, and Centrifuge. 39. Incubate at $50^{\circ} \mathrm{C}$ for 1 hour. 40. **Prepare PCR Master Mix:** Reagent Volume $\backslash(\underline{\mu})_{-}$Ultra Pure

Water 8.5 PCR Mix 25 RNA PCR Primer Total

Volume per Sample $\quad 35.541$. Add $35.5 \mu \mathrm{L}$ of PCR Master Mix to each tube. 42. Add $2 \mu \mathrm{L}$ of unique PCR Primer Index to each tube. \(Total volume is $50 \mu \mathrm{L}$.) 43. Gently mix and centrifuge. 44. PCR Program: $98^{\circ} \mathrm{C} 30 \mathrm{sec} .1 \mathrm{X}$

- $\quad 72^{\circ} \mathrm{C} 10 \mathrm{~min} . \quad 1 \mathrm{X} \quad 4^{\circ} \mathrm{C} \quad$ Hold ${ }^{*}$ Quality Control** 1 . Bioanalyzer High Sensitivity DNA $98^{\circ} \mathrm{C} 10 \mathrm{sec}$. $60^{\circ} \mathrm{C} 30 \mathrm{sec} .20 \mathrm{X} \quad 72^{\circ} \mathrm{C} 15 \mathrm{sec}$. Chip \(Library peak should be 152bp.) **Size Selection - Pippin Prep:** 1. Can either pool libraries or run libraries independently. 2. Purify libraries with QIAquick PCR Purification kit $\backslash(5 \mu \mathrm{g})$. Elute in $10 \mu \mathrm{L}$ water. 3. Nanodrop purification - Add no more than $5 \mu \mathrm{g}$ of PCR product, minimum in low nanograms. 4. For each lane, bring total volume of library $\backslash(\mathrm{s})+\mathrm{TE}$ buffer to $30 \mu \mathrm{L}$. 5. Add $10 \mu \mathrm{L}$ of supplied loading buffer $\backslash$ (at RT). 6. Size select for $152 \mathrm{bp}$. Device-to-device variation likely. Make sure to save some PCR product for optimizing. Our program is set at 117-146 Range. 7. Bioanalyzer HS DNA Chip \(Peak at 152bp ONLY - may see some adapter-dimer and $\sim 160$ bp peaks.) 


\section{Troubleshooting}

1) Oligonucleotide sequences () 2016 Illumina, Inc. All rights reserved. Derivative works created by Illumina customers are authorized for use with Illumina instruments and products only. All other uses are strictly prohibited. 2) Do not use the ligation buffer supplied with the T4 RNA Ligase 2, Deletion Mutant. This enzyme retains activity in ligation buffer. 3) Dilute $25 \mathrm{mM}$ dNTP 1:1 to a final concentration of 12.5 $\mathrm{mM}$.

\section{References}

1) Jayaprakash $A D$, Jabado $O$, Brown BD, Sachidanandam R. 2011. Identification and remediation of biases in the activity of RNA ligases in small-RNA deep sequencing. _Nucleic Acids Research_**39**: e141. 2) Sorefan K, Pais H, Hall AE, Kozomara A, Griffiths-Jones S, Moulton V, Dalmay T. 2012. Reducing ligation bias of small RNAs in libraries for next generation sequencing. _Silence_ ${ }^{* \star} 3^{\star *}$ : 4. 3) Zhang Z, Lee JE, Riemondy K, Anderson EM, Yi R. 2013. High-efficiency RNA cloning enables accurate quantification of miRNA expression by deep sequencing. _Genome Biology_ ${ }^{\star *} 14 * *$ : R109. 4) Zhuang F, Fuchs RT, Sun Z, Zheng Y, Robb GB. 2012. Structural bias in T4 RNA ligase-mediated 3'-adapter ligation. _Nucleic Acids Research_**40**: e54. 5) Hafner M, Renwick N, Brown M, et al. 2011. RNA-ligase-dependent biases in miRNA representation in deep-sequenced small RNA cDNA libraries. _RNA_**17**:1697-1712.

\section{Acknowledgements}

This protocol was modified from the manufacturer's instructions for the TruSeq Small RNA Library Preparation Kit. 